\title{
UMA EXPERIÊNCIA DE GEOMETRIA PLANA COM TECNOLOGIAS NO ENSINO BÁSICO: UM OLHAR A PARTIR DA TEORIA DE VAN HIELE
}

\author{
Rodrigo Sychocki da Silva* \\ Rose Grochot Gayeski**
}

\begin{abstract}
Resumo: O presente artigo tem como objetivo apresentar e analisar os resultados de uma sequência de atividades desenvolvidas no software GeoGebra e feitas com estudantes do Ensino Médio. O conteúdo desenvolvido nas atividades foi o de Geometria Plana com ênfase em polígonos e quadriláteros notáveis. $\mathrm{O}$ artigo tece também reflexões sobre como a tecnologia pode potencializar e auxiliar o professor no ensino da Geometria. As atividades desenvolvidas tiveram o aporte teórico no modelo de pensamento geométrico de Van Hiele e a utilização dos recursos tecnológicos em sala de aula está fundamentada em uma perspectiva teórica conforme os autores estudados. A reflexão aqui apresentada é fruto de um estudo qualitativo, no qual se utilizou o software GeoGebra como recurso tecnológico. Como intuito de averiguar o desenvolvimento de competências e habilidades geométricas foi realizado com a turma durante o experimento de ensino um pré-teste e um pós-teste. A título de conclusão infere-se que o experimento de ensino possibilitou aos estudantes avançar progressivamente na construção de conhecimentos sobre polígonos e quadriláteros notáveis; e ao professorpesquisador, refletir sobre a qualidade do ensino da geometria quando se integram recursos tecnológicos ao fazer docente.
\end{abstract}

Palavras-chave: Geometria. Ensino. Aprendizagem. Tecnologias Digitais.

\section{Introdução}

A sociedade contemporânea é caracterizada pela globalização, em que as informações e a velocidade com que elas nos atingem transformam os ambientes familiares, sociais e culturais das pessoas. As facilidades de acesso e quantidade de informações influenciam também o ambiente escolar. Percebe-se um desinteresse dos educandos em sala de aula que segundo Guimarães (2013, p.11) é "fruto da incoerência entre o modo de ensinar e os modos pelos quais os sujeitos contemporâneos lidam com o conhecimento". Sendo assim, os métodos que são usados contemporaneamente para ensinar, por vezes não atendem as novas formas de aprender, ser, agir, sentir, expressar e comunicar-se dos estudantes inseridos nesse mundo cibercultural.

\footnotetext{
* Universidade Federal do Rio Grande do Sul (UFRGS). Departamento de Matemática Pura e Aplicada. Programa de Pós-Graduação em Ensino de Matemática. Doutor em Informática na Educação (UFRGS). E-mail: sychocki.rodrigo@gmail.com

Universidade Federal do Rio Grande do Sul (UFRGS). Departamento de Matemática Pura e Aplicada. Programa de Pós-Graduação em Ensino de Matemática. Mestranda do curso de Pós-Graduação em Ensino de Matemática (UFRGS), modalidade acadêmico. E-mail: seduc.proferose@gmail.com
} 
Diante da fala de Guimarães (2013) percebe-se a cada dia a necessidade de elaborar aulas que atendam às necessidades dos estudantes, principalmente os da educação básica, uma vez que praticamente nascem inseridos em um mundo predominantemente cibercultural. Contudo, os aparatos tecnológicos disponíveis podem potencializar o processo de ensino e oportunizar a aprendizagem, auxiliando na explanação de conteúdos, em particular os da geometria. Na escolha de algum recurso tecnológico, surge como possibilidade o software GeoGebra, no qual Notare e Basso $(2012$, p. 5) afirmam que o mesmo se trata de: "Um software que apresenta potencial para melhorar a abordagem dada à Matemática nas escolas é o GeoGebra um software de geometria dinâmica, no qual é possível trabalhar, simultaneamente, com geometria e álgebra".

A geometria é um dos tópicos da matemática trabalhado a partir das séries iniciais e merece atenção por parte dos educadores. Ela permite a construção e desenvolvimento de conceitos geométricos fundamentais que convergem para o desenvolvimento cognitivo do aluno, porém, nota-se com a prática docente que os estudantes apresentam dificuldades de compreensão de propriedades, formas e argumentações que envolvem objetos geométricos.

Segundo Gravina (1996) parte dessa dificuldade tem origem nos programas e práticas de ensino. Os livros didáticos, por exemplo, iniciam com definições nem sempre claras e com desenhos particulares de figuras planas, que induzem o aluno a acreditar que o retângulo, por exemplo, só tem aquele formato apresentado, fazendo com que o educando passe a deduzir as características da figura só naquele aspecto figural, sem entender o campo conceitual, provocando assim, desequilíbrios na formação de conceitos. Ainda segundo a autora, o aspecto de construção de objetos geométricos é dificilmente abordado nos livros, mesmo sabendo que esse tipo de atividade oportunizaria ao estudante a construção de tais conceitos.

Com vistas a estimular a participação e o interesse dos estudantes em sala de aula, bem como oportunizar o estudo e posterior construção de conceitos matemáticos foi desenvolvida e aplicada uma sequência de atividades sobre Geometria Plana. As mesmas foram pensadas a partir de uma leitura sobre a construção do pensamento geométrico de Van Hiele e no uso de um recurso tecnológico, no caso o software GeoGebra. No experimento de ensino, de cunho qualitativo, procurou-se investigar como a utilização de um software de geometria dinâmica contribui no ambiente de ensino, enfatizando-se quais as características positivas que a utilização deste software proporciona no ensino de Geometria Plana.

Na sequência apresenta-se uma revisão de literatura sobre o ensino de Geometria Plana embasada no pensamento geométrico de Van Hiele segundo Oliveira (2008), Schirlo e 
Silva (2010), Vieira (2010), Schirlo et al. (2014), Heinen e Basso (2015) e Crowley (1994). Além disso, descreve-se a sequência didática seguida da análise de resultados baseada no pensamento geométrico de Van Hiele e no uso de recursos tecnológicos tendo como amparo teórico Guimarães (2013), Gravina e Contiero (2011), Maltempi (2008) e Notare e Basso (2012).

\title{
2 Ensino e aprendizagem da Geometria com viés no modelo de Van Hiele
}

A geometria faz parte das construções realizadas pelo homem e pela natureza. Mesmo sem perceber, conceitos geométricos são usados e fazem parte do nosso cotidiano, logo conhecer, refletir e aprender ideias da geometria parece ser um encaminhamento necessário desde o ensino básico, pois se faz necessário que o sujeito leia e compreenda o mundo a sua volta. Na prática o discurso sobre a aprendizagem da geometria mostra-se diferente. Para construir conceitos geométricos, segundo Oliveira (2008) é necessário desenvolver relações perceptivas e raciocínio lógico. Por vezes os estudantes apresentam dificuldades para desenvolver tais relações. Segundo Borsoi (2016) isso pode estar relacionado à falta de experimentação e manipulação de figuras e objetos geométricos, uma vez que, nas escolas a ênfase está predominantemente em fórmulas.

Nesta linha de pensamento Notare e Basso (2012) afirmam que:

\begin{abstract}
Normalmente, o que se observa, é um sucesso aparente dos alunos na resolução de problemas. Isso ocorre porque, geralmente, as aulas de Matemática escolar reforçam a simples utilização e reprodução de procedimentos e algoritmos, enfatizando roteiros ou modelos a serem seguidos na resolução de problemas. Dessa forma, o que ocorre é a aprendizagem de um conjunto de procedimentos padrão, que possibilita a resolução de uma classe de problemas extremamente limitada; os alunos adquirem apenas a capacidade de efetuar cálculos, sem compreendê-los. Esse processo está longe do verdadeiro fazer matemática, que exige habilidades como conjecturar, testar, intuir, deduzir, generalizar - coordenar ações e retirar dessas coordenações novas coordenações, por abstrações refletidas. (NOTARE e BASSO, 2012, p. 2)
\end{abstract}

Então, constata-se ser necessário que o ensino da geometria deva privilegiar a manipulação de materiais concretos ou softwares, com o intuito de potencializar o desenvolvimento de competências e habilidades geométricas por parte dos estudantes.

Na Base Nacional Comum Curricular (BRASIL, 2016) o estudo da geometria, tem o objetivo de retomar, ampliar e sintetizar os conhecimentos já estudados, a fim de permitir que o aluno entenda a estrutura lógica da geometria euclidiana, visando retomar as demonstrações já iniciadas e ampliá-las, permitindo a compreensão e generalização de propriedades e teoremas. Portanto, é fundamental identificar o conhecimento prévio do estudante e propor 
atividades investigativas que estimulem a aprendizagem e proporcionem condições para que o estudante possa construir seu próprio conhecimento.

O modelo proposto pelos Van Hiele (apud Oliveira, 2008, Crowley, 1994) apresenta-se como um instrumento para avaliar as habilidades geométricas dos educandos. O modelo tem duas fases complementares: descritiva e prescritiva. Na fase descritiva busca-se explicar como os estudantes pensam, em relação à geometria de acordo com cinco níveis de pensamento: visualização, análise, dedução informal, dedução formal e rigor. $\mathrm{Na}$ fase prescritiva constroem-se caminhos a seguir durante o processo de ensino da geometria, para que o estudante possa desenvolver seu pensamento, de acordo com cinco fases de aprendizagem: interrogação, orientação dirigida, explicação, orientação livre e integração.

A partir da leitura de trabalhos desenvolvidos por Oliveira (2008), Schirlo e Silva (2010), Vieira (2010), Schirlo et al. (2014) e Heinen e Basso (2015), os quais utilizaram a teoria de Van Hiele, sintetizou-se a tabela abaixo, os cinco níveis de pensamento geométrico que originalmente eram numerados de 0 a 4 e na literatura atual são numerados de 1 a 5 .

Tabela 1 - Organização e apresentação dos níveis de Van Hiele a partir de pesquisas desenvolvidas por Oliveira (2008), Schirlo e Silva (2010), Vieira (2010), Schirlo et al. (2014) e Heinen e Basso (2015).

\begin{tabular}{|c|c|c|}
\hline Nível & Classificação & Características \\
\hline 1 & $\begin{array}{l}\text { Visualização ou } \\
\text { reconhecimento }\end{array}$ & $\begin{array}{c}\text { Nesse nível o aluno apenas observa e compara de maneira global } \\
\text { as figuras, mas não consegue caracterizá-las ou conceituá-las. O } \\
\text { reconhecimento é feito somente pela aparência e pela forma e } \\
\text { não por suas propriedades. }\end{array}$ \\
\hline 2 & Análise & $\begin{array}{l}\text { Para o aluno esse nível se caracteriza pelo reconhecimento das } \\
\text { características e propriedades das figuras, ocorre por meio da } \\
\text { manipulação e observação. No entanto ainda são incapazes de } \\
\text { fazer correlações entre as propriedades e definir conceitos. }\end{array}$ \\
\hline 3 & $\begin{array}{l}\text { Dedução } \\
\text { Informal }\end{array}$ & $\begin{array}{l}\text { O aluno consegue produzir relações entre as propriedades das } \\
\text { figuras deduzindo-as de forma simples. Também é capaz de } \\
\text { acompanhar argumentos em uma demonstração, porém, não } \\
\text { consegue desenvolver sozinho demonstrações formais. }\end{array}$ \\
\hline 4 & Dedução formal & $\begin{array}{l}\text { Nessa etapa o aluno consegue identificar as características, pode } \\
\text { construir demonstrações e fazer relações com outros conceitos, } \\
\text { porém não utiliza muito rigor matemático. }\end{array}$ \\
\hline 5 & Rigor & $\begin{array}{c}\text { Nesse nível o aluno estabelece relações, comparações entre } \\
\text { teoremas, propriedades e conceitos, não necessita de materiais } \\
\text { manipuláveis, consegue fazer de forma abstrata. }\end{array}$ \\
\hline
\end{tabular}
Fonte: Autores.

O desenvolvimento do pensamento dentro desses cinco níveis ocorre por meio de experiências e atividades pensadas, em uma sequência didática, com grau de dificuldade gradual. Dessa forma, um estudante pode estar em um nível para uma determinada atividade, e em outro para outras. Por meio dos níveis é possível identificar a maturidade geométrica dos 


\section{\#tear}

educandos e ajudá-los a avançar no percurso de construção dos conceitos matemáticos inerentes a geometria.

\section{Ensino de Matemática, Recursos Tecnológicos e Geometria}

$\mathrm{Na}$ atualidade o ritmo imposto para a construção de saberes matemáticos, segundo Guimarães (2013) por meio da dinâmica cibercultural, é muito mais "sedutor" do que a aprendizagem baseada na cultura impressa. $\mathrm{O}$ educando demanda cada vez mais um ambiente e um processo metodológico que oportunize o desenvolvimento de uma aprendizagem significativa e contextualizada, que promova a investigação e garanta o desenvolvimento de competências e habilidades, em oposição aos métodos de ensino que priorizam decorar fórmulas sem estabelecer relações entre os objetos e o mundo estudado.

Segundo Maltempi (2008) vive-se em uma sociedade em que grande parte da população está em crescente contato com a tecnologia, proporcionando novas formas de viver, de trabalhar e de se organizar. Nesse sentido a escola recebe esses usuários de tecnologias e isso amplia as possibilidades de ensinar e aprender, permitindo ao professor, novas e variadas formas para o desenvolvimento do processo de aprendizagem que façam uso dessas tecnologias. Portanto, tais recursos criam ambientes de aprendizagem que estimulam novas formas de pensar, agir e investigar.

Nas palavras de Gravina e Contiero (2011) com os recursos tecnológicos é possível estabelecer um ambiente de aprendizagem em sala de aula diferente, estimulador e investigador, que contribui no desenvolvimento de habilidades cognitivas, permitindo a interação de conteúdo, que normalmente são estudados separadamente e sem conexão. Portanto relacionar um software com uma metodologia de investigação pode tornar a aula dinâmica e desafiadora, possibilitando que os estudantes criem suas conjecturas, estratégias, testem e avaliem soluções fazendo-se uso de softwares.

Um recurso tecnológico que se faz presente na atualidade é o software GeoGebra que proporciona estabelecer relações entre imagens mentais e a representação na tela do computador. A manipulação de objetos no software permite representar, descrever e compreender formas geométricas presentes na sociedade em que o educando está inserido. $\mathrm{O}$ software GeoGebra é um programa de matemática dinâmica que pode ser usado em todos os níveis de ensino, que reúne conceitos e propriedades geométricas, álgebra, planilhas, gráficos, estatísticas e cálculo. Oportuniza a construção de figuras geométricas que ao serem movimentadas podem manter as propriedades. Seus arquivos podem ser facilmente 
compartilhados, é um software livre, de fácil manuseio e pode ser instalado em computadores, tablets, smartphone e outros dispositivos.

\section{Procedimentos metodológicos: materiais e métodos}

O objetivo da sequência de atividades foi identificar e analisar as propriedades dos polígonos com ênfase nos quadriláteros notáveis paralelogramos e trapézios, sendo que a partir do estudo e compreensão das propriedades construiu-se, a título de produto da sequência de atividades, mosaicos. As atividades foram úteis também para construir e estudar as relações matemáticas para o cálculo da área dos quadriláteros notáveis.

Em consonância com esses objetivos a abordagem da presente pesquisa foi qualitativa procurando descrever de forma detalhada a participação e evolução dos educandos no decorrer do processo, de acordo com o modelo de Van Hiele. Conforme os autores Bogdan e Biklen (1994) a pesquisa qualitativa descreve os aspectos não mensuráveis do espaço educacional, valoriza os aspectos descritivos e individuais, procurando compreender o contexto e se importando com o processo e não só com os resultados, sendo que os sujeitos da pesquisa são os co-autores da investigação.

O grupo da pesquisa foi uma turma do primeiro ano do Ensino Médio, composta por 15 estudantes, da Escola de Ensino Médio Rainha da Paz. Trata-se de uma instituição localizada no município de Serafina Corrêa, no estado do Rio Grande do Sul. As atividades foram desenvolvidas no período de 19 de outubro a 09 de novembro de 2017, durante os períodos de aula da disciplina de matemática.

A construção da sequência de atividades foi inspirada nas ideias de Silva et al. (2016), que usou os princípios da Engenharia Didática francesa como uma metodologia de investigação, ou seja, aqui também assume-se que durante o fazer didático cabe ao professor repensar a sua prática enquanto atuante em sala de aula, readequando-a se necessário, durante a execução e permitindo que a realidade escolar se torne um ambiente de reflexão e de encaminhamento de propostas inovadoras.

A coleta de dados foi realizada por meio de registros escritos feitos pelos estudantes durante as tarefas e pela professora a partir das observações, além de imagens da tela do software no momento das construções e fotos.

Também foram aplicados dois testes, sendo um antes da realização da sequência de atividades e outro após, para que se pudesse avaliar o desenvolvimento de conceitos e 


\section{\#tear}

habilidades geométricas. Antes do desenvolvimento das atividades foram estabelecidas as seguintes hipóteses:

a) Hipótese 1: Os alunos não tem familiaridade com o software e as dificuldades iniciais de manuseio poderão ser minimizadas com a apresentação das ferramentas;

b) Hipótese 2: Os alunos têm conhecimento prévio sobre conceitos envolvidos nas atividades;

c) Hipótese 3: O trabalho em grupo e o uso do software GeoGebra proporcionarão investigação, discussão, reflexão e construção de conhecimento.

Almejava-se que ao final das atividades os alunos tivessem condições de reconhecer e identificar características, propriedades e calcular a área dos polígonos e quadriláteros notáveis, bem como identificar o número de diagonais, a medida e a soma dos ângulos internos de um polígono. A sequência de atividades desenvolvida com a turma do primeiro ano, do ensino médio foi organizada da seguinte maneira:

a) $1^{\mathrm{o}}$ dia: o objetivo inicial foi aplicar o pré-teste e conhecer as ferramentas do software GeoGebra.

b) $2^{\circ}$ dia: a segunda atividade tinha como objetivo, por meio de construções no GeoGebra, estudar os polígonos priorizando a classificação em convexos e côncavos, regulares e irregulares, ângulos internos e externos, diagonais e nomenclatura.

c) $3^{\circ}$ dia: nesse dia a atividade foi de caráter investigativo e a professora atuou como orientadora do processo. Foram exploradas as propriedades dos polígonos regulares através das construções dinâmicas do GeoGebra, que foram disponibilizadas por meio de links ${ }^{1}$. Os estudantes também desenvolveram as atividades referentes aos assuntos estudados até o momento, no material utilizado pela escola.

d) $4^{\circ}$ dia: a partir de passos fornecidos pela professora os alunos construíram no GeoGebra um quadrilátero regular inscrito em quadrilátero irregular. Movimentaram a construção e exploraram as propriedades.

e) $5^{\circ}$ dia: nesse dia os estudantes realizaram construções de paralelogramos e de trapézios no GeoGebra de acordo com características e propriedades desses quadriláteros com o objetivo de que ao serem movimentados na tela do computador os mesmos não se deformassem.

\footnotetext{
${ }^{1}$ Disponíveis em: https://www.geogebra.org/m/AdZFMsGm, https://www.geogebra.org/m/QYYtaT9Dhttps://www.geogebra.org/m/Zv6FMVP9 (Acesso em outubro de 2017)
} 
f) $6^{\circ}$ dia: identificar "maneiras", ou seja, relações matemáticas para calcular a área de algumas figuras planas (quadriláteros notáveis) a partir da manipulação de construções no GeoGebra disponíveis nos links ${ }^{2}$ fornecidos pela professora.

g) $7^{\circ}$ dia: construir mosaicos no software GeoGebra e responder ao pós-teste.

A próxima seção busca apresentar os resultados obtidos com o desenvolvimento das atividades, analisar, discutir e refletir à luz do referencial teórico sobre a construção de conhecimento matemático pelos estudantes. Refletir também sobre a importância, contribuições e desafios que o uso da tecnologia proporcionou durante o processo de experimentação aqui exposto.

\section{Análise e discussão dos resultados obtidos}

Inicialmente foi realizada a avaliação do conhecimento prévio dos estudantes por meio de um pré-teste, onde se constatou que $80 \%$ da turma, segundo o modelo de Van Hiele, encontravam-se no nível 1 de pensamento geométrico ou em partes do nível 1. Observou-se que apesar de conseguir classificar a maioria das figuras planas, a maioria dos estudantes ainda não reconhecia as propriedades geométricas das mesmas.

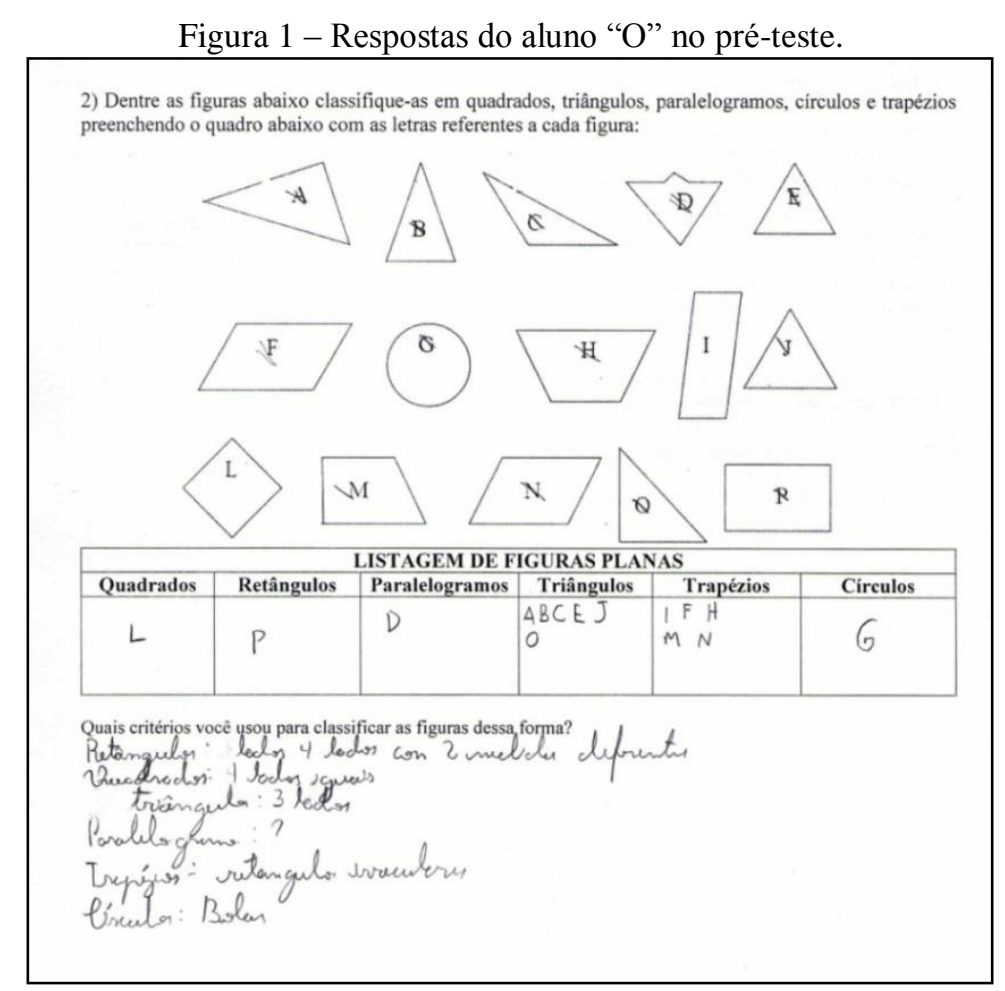

Fonte: arquivo pessoal.

2 Disponíveis em: https://www.geogebra.org/m/D8rjsGzF, https://www.geogebra.org/m/ZeDN7ZTW e https://www.geogebra.org/m/ggpaFhA4. (Acesso em outubro de 2017) 
A outra parte da turma encontrava-se no nível 2, em que já reconhecia características das figuras, porém não conseguia na ocasião fazer a dedução informal das propriedades, como mostrado na forma de exemplo na figura a seguir.

Figura 2 - Resposta do aluno "M" na atividade 4 do pré-teste.

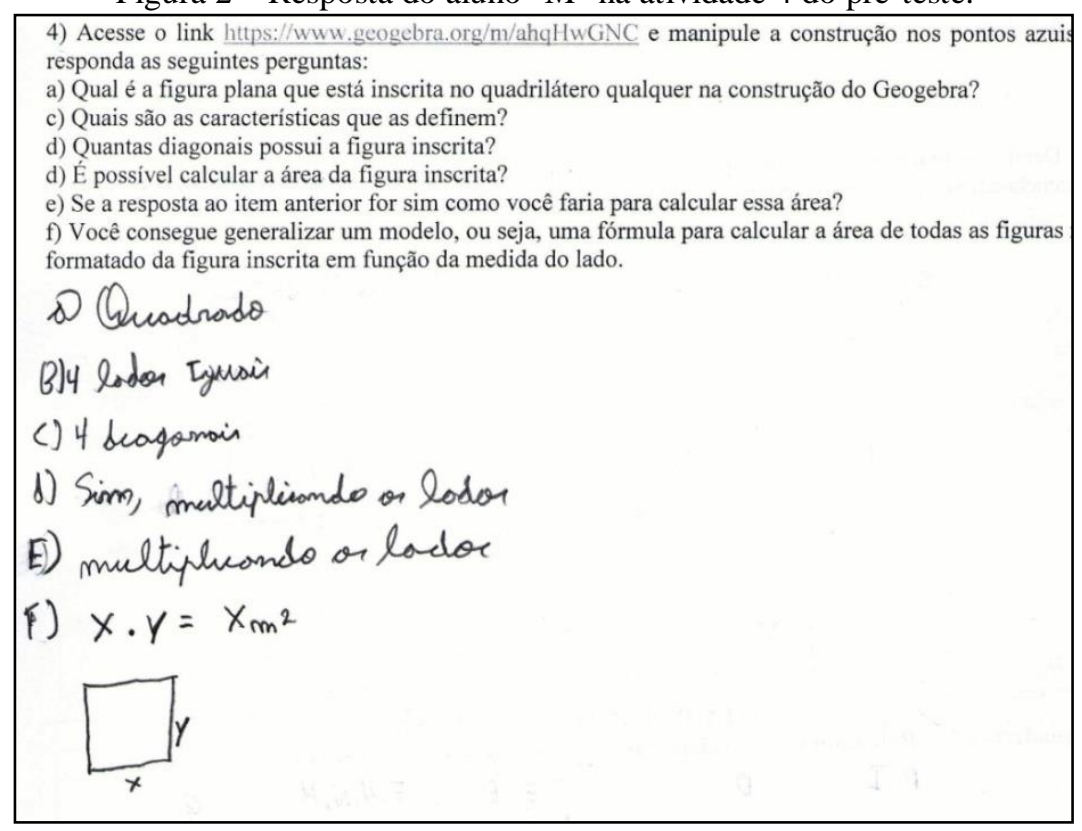

Fonte: arquivo pessoal.

A primeira atividade da sequência foi conhecer o software GeoGebra, pois os estudantes não haviam tido o contato com o mesmo, tornando possível esclarecer a primeira hipótese. Todas as atividades desenvolvidas na sequência foram feitas em duplas ou em trios com o objetivo de proporcionar a discussão sobre os conceitos estudados. No segundo encontro, a atividade foi conhecer os polígonos priorizando a classificação em convexos e côncavos, regulares e irregulares, ângulos internos e externos, diagonais e nomenclatura. Essa atividade investigativa foi desenvolvida por meio de construções no GeoGebra, sob orientação da professora, seguidas de exploração das características, pois de acordo com o modelo de Van Hiele, uma das fases de aprendizagem é a orientação dirigida, em que os estudantes são orientados pelo professor na execução de atividades previamente preparadas. Os conceitos matemáticos nessa fase são assimilados de forma progressiva.

Nessa atividade constatou-se que 11 estudantes da turma avançaram para o nível 2, segundo o modelo de Van Hiele no decorrer da atividade, reconhecendo características dos polígonos e utilizando-as de forma correta, como pode ser observado na Figura 3. 


\section{\#tear}

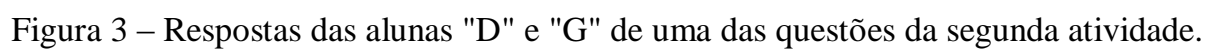

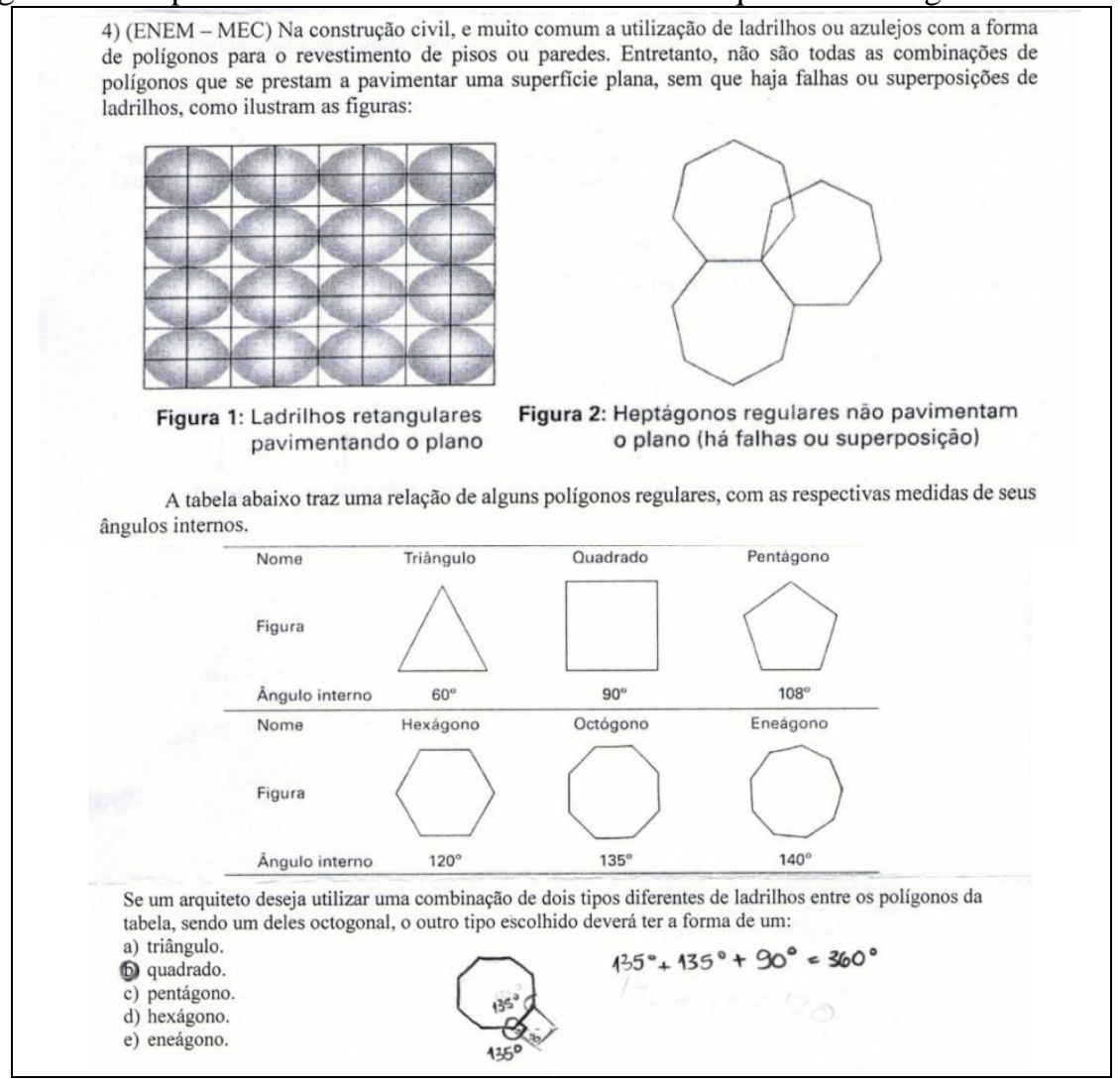

Fonte: arquivo pessoal.

No terceiro dia, sob orientação da professora foram exploradas as propriedades dos polígonos regulares, que já tinham sido construídos previamente no GeoGebra. A figura 4 mostra o avanço de um trio de estudantes no nível de pensamento geométrico. O trio passa a analisar e descrever as características por meio da manipulação de objetos, porém ainda foram incapazes de conceituar precisamente. 


\section{\#tear}

Figura 4 - Exercício e respostas das alunas "A", "B" e "C" sobre características dos polígonos.

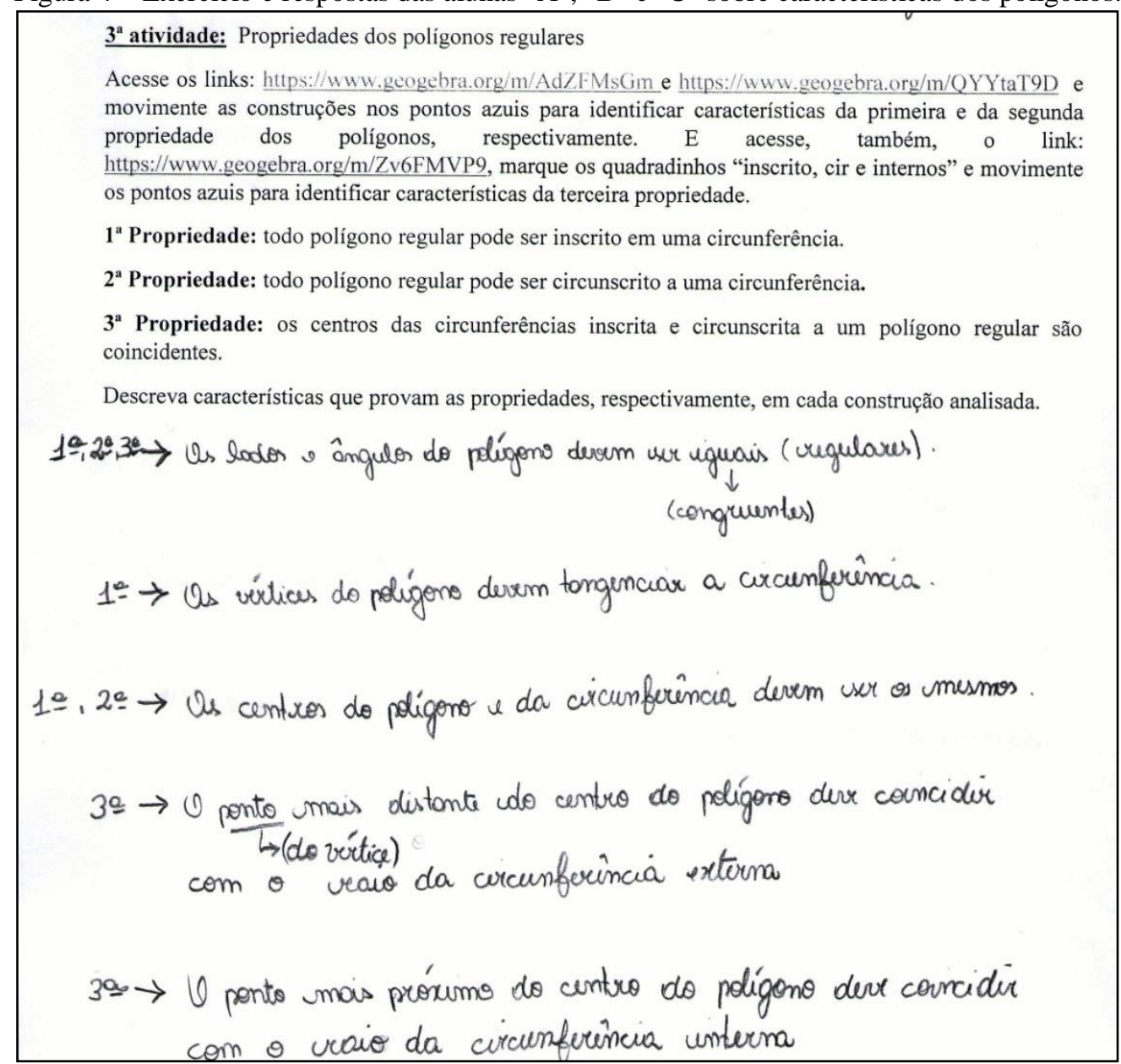

Fonte: arquivo pessoal.

A quarta atividade realizada estava de acordo com a primeira fase do modelo de Van Hiele, em que foi possível identificar o conhecimento prévio do estudante sobre quadriláteros, a partir da construção conjunta, seguindo passos de construção que foram fornecidos pela professora, de quadrilátero regular e irregular. Após as construções, fez-se uso das ideias de Silva et al. (2016) para repensar e reorganizar as próximas atividades, pois identificou-se que mais da metade da turma já tinha aprendido as características das figuras construídas.

A atividade proposta na sequência estava baseada no nível dois do modelo. Nessa atividade os participantes realizaram a construção dos quadriláteros notáveis de acordo com as propriedades para que ao serem movimentados, não se deformassem. De acordo, com Gravina e Contiero (2011) o GeoGebra é um software de geometria dinâmica que permite fazer isso, que ao movimentar os pontos livres a construção se transforma quanto ao tamanho e posição, porém preserva as propriedades geométricas que foram utilizadas no processo de construção. Os estudantes utilizaram como apoio o material disponibilizado pela escola, para em um processo de investigação, ou seja, buscaram apoio teórico sobre as propriedades e 
realizaram a construção de paralelogramos (quadrado, retângulo, losango) e trapézios com sucesso.

Durante o processo a professora mediou a investigação dos estudantes, instigando-os a refletir sobre as conjecturas e hipóteses construídas. Observou-se que apenas um grupo não conseguiu realizar a atividade de forma satisfatória, comprovando assim que a maioria deles atingiu o nível dois, podendo avançar. Como forma de um fechamento pontual da atividade os estudantes sistematizaram os conhecimentos por meio de exercícios que foram indicados no material já utilizado na escola.

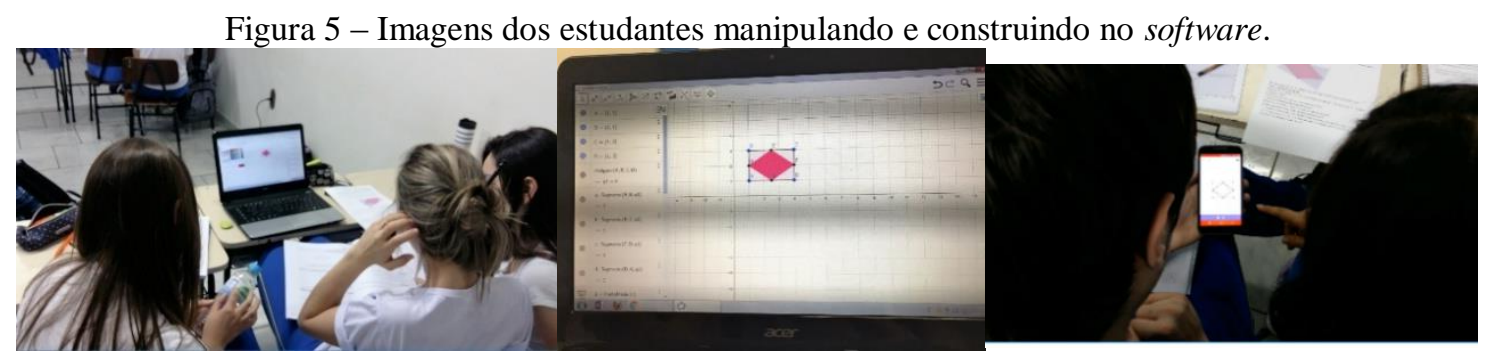

Fonte: arquivo pessoal.

$\mathrm{Na}$ sexta atividade, por meio da fase de explicação do modelo de Van Hiele, inicialmente, a professora falou da área do quadrado e do retângulo, usando como modelo o piso da sala de aula. Na sequência os alunos acessaram os links ${ }^{3}$, para que a partir da movimentação pudesse de alguma forma ser deduzida a relação para o cálculo da área dos demais quadriláteros de maneira informal.

Observou-se neste momento que só um grupo manifestou dificuldade para conjecturar a fórmula do losango. Os demais atingiram o nível 3 do modelo de Van Hiele nessa atividade.

A última atividade foi a partir dos polígonos e das propriedades dos polígonos estudados que fosse construído uma figura de mosaico. Foi solicitado aos estudantes, com antecedência, que observassem e fotografassem construções da cidade, nos ambientes da casa deles, nas roupas, nos utensílios, tapetes, potenciais exemplos de mosaicos para serem recriados no software GeoGebra. Com essa atividade foi possível analisar o nível de conhecimento dos participantes, verificando que a maioria deles atingiu o nível 3 (Figura 6), sendo que só um grupo construiu um mosaico que se de formava ao movimentar os pontos livres.

\footnotetext{
3 Disponíveis em: https://www.geogebra.org/m/D8rjsGzF, https://www.geogebra.org/m/ZeDN7ZTw ,https://www.geogebra.org/m/ggpaFhA4 (Acesso em outubro de 2017)
} 


\section{\#tear}

Figura 6 - Imagem dos mosaicos construídos no software com adaptação de cores.

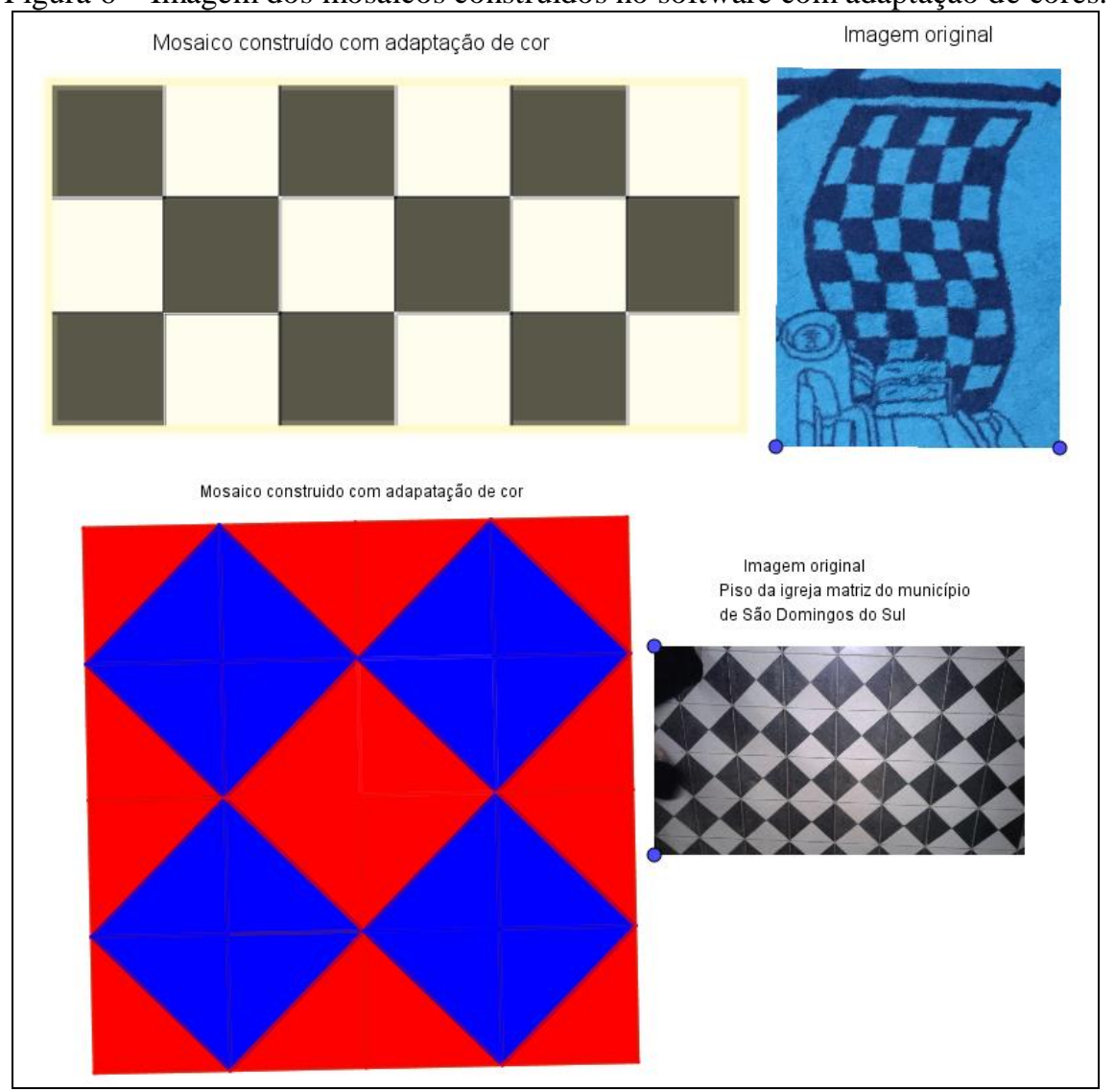

Fonte: arquivo pessoal.

Com relação às hipóteses 1 e 2 mencionadas na seção quatro do presente artigo, notase que ambas foram confirmadas, pois os estudantes tinham conhecimento prévio e com o passar das aulas as dificuldades no uso do software foram minimizadas.

Observa-se que a terceira hipótese foi comprovada em partes. Mostrou-se profícua e importante a troca de ideias que ocorre no trabalho em grupo e da potencialidade que o software tem para estabelecer caminhos que auxiliam e facilitam o processo de investigação e construção do conhecimento (Figura 7). Observou-se que somente um grupo não conseguiu deduzir de maneira informal a fórmula da área do losango e ainda nas atividades do pós-teste verificou-se que $90 \%$ dos estudantes conseguiram desenvolver a maioria das atividades propostas de forma satisfatória, alcançando assim o terceiro nível do modelo de Van Hiele. 
Figura 7 - Relato da aluna E.

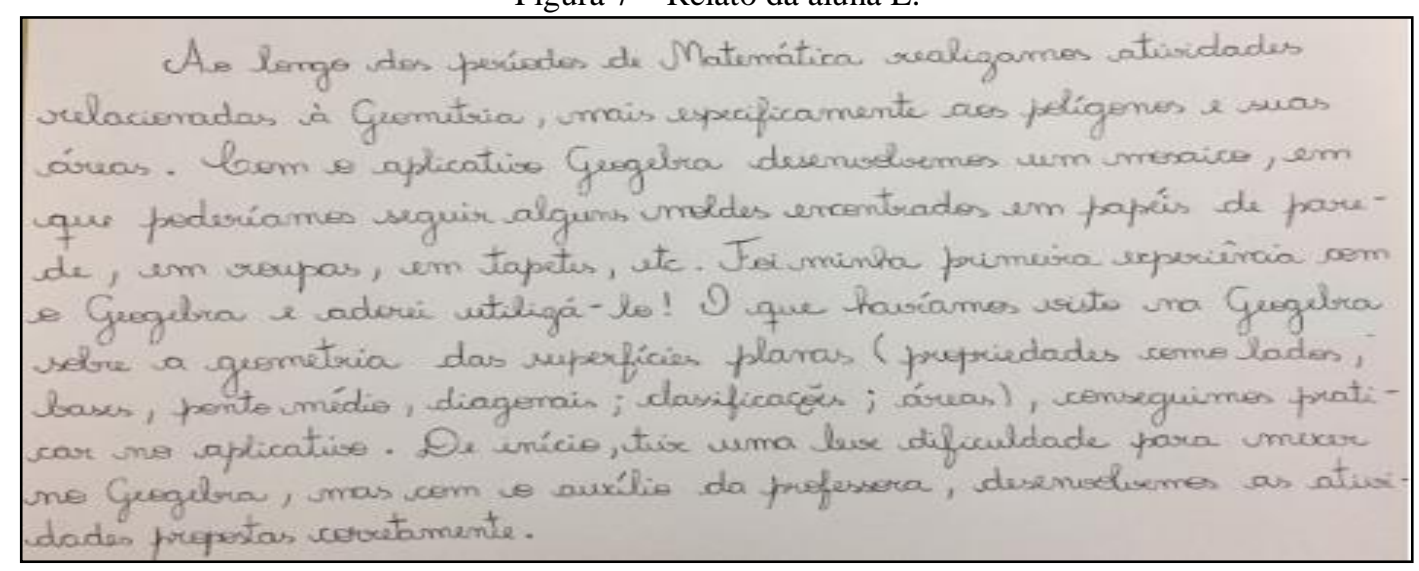

Fonte: arquivo pessoal.

\section{Reflexões finais}

Em relação aos resultados obtidos com a aplicação da sequência de atividades, conclusões e contribuições podem ser elencadas. Na introdução foi mencionado que muitas das dificuldades manifestadas pelos estudantes no estudo da geometria diz respeito a forma (método, recursos, livros) como é trabalhado o conteúdo em sala de aula. Com um olhar nos resultados apresentados nesse artigo, nota-se que a partir do momento que o professor produz uma série de atividades que façam uso da tecnologia, a aula se insere no contexto de mundo cibercultural, sendo este um novo lugar de investigação, o qual se estabelece diante das construções, uma vez que, o aluno passa a ser o protagonista da própria aprendizagem.

As atividades que foram desenvolvidas no software buscaram explorar o pensamento geométrico com os recursos de visualização por meio da Geometria Plana, com ênfase no movimento das figuras para conjecturar propriedades, estabelecer relações e conseguintemente, criar novas construções, identificar diagonais, ângulos e áreas.

O experimento de ensino oportunizou a instauração de um processo ativo e interativo de discussão e argumentação por meio da manipulação de construções no software. Os estudantes foram construindo seu próprio conhecimento à medida que realizavam as atividades, trocando ideias com os seus colegas de grupo, por meio dos questionamentos que apareciam na sequência dos problemas direcionados pela professora e outros que surgiam no decorrer das atividades.

Ocorreram imprevistos durante o processo de execução da proposta. Como a escola não possui laboratório de informática foi solicitado aos grupos que fizessem o download do software em um notebook particular, sendo que, um dos grupos chegou à aula sem o software 
instalado, precisando isso ser feito antes das atividades. Outro empecilho ocorreu na sexta atividade, no qual a internet da escola não estava funcionando adequadamente, tendo que se utilizar o celular e a internet do próprio aparelho para realizar a atividade. Nota-se com essa atitude o fator persistência do professor envolvido com o fazer docente em sala de aula. Ao invés de desistir e mudar o encaminhamento metodológico das atividades buscou-se elaborar estratégias que pudessem se mostrar eficientes para a execução da proposta e que mantivessem presente o uso das tecnologias.

Ao final, destaca-se que o presente artigo buscou mostrar uma forma de inserção da tecnologia no âmbito escolar durante o ensino de Geometria Plana, de acordo com o modelo de Van Hiele. O uso do software GeoGebra possibilitou a criação de uma experiência nova, uma vez que os estudantes ainda não o tinha utilizado. À medida que os estudantes avançavam de nível, o pensamento geométrico também evoluía de qualidade. Por isso, constata-se que ao inserir nas aulas de matemática uma proposta metodológica como a relatada neste artigo reafirma-se o compromisso e responsabilidade que cada professor deve ter com o processo de ensino e aprendizagem ao longo do desenvolvimento do estudante durante sua vida escolar, tornando o conhecimento algo que oportunize evolução.

\title{
AN EXPERIENCE OF FLAT GEOMETRY WITH TECHNOLOGIES IN BASIC EDUCATION: A LOOK FROM THE VAN HIELE THEORY
}

\begin{abstract}
The present article aims to present and analyze the results of a sequence of activities developed in GeoGebra software and made with high school students. The content developed in the activities was that of Flat Geometry with emphasis on polygons and remarkable quadrilaterals. The article also discusses how technology can enhance and assist teachers in the teaching of Geometry. The activities developed had the theoretical contribution in the Van Hiele geometric thinking model and the use of technological resources in the classroom is based on a theoretical perspective according to the authors studied. The reflection presented here is the result of a qualitative study, in which GeoGebra software was used as the technological resource. In order to ascertain the development of geometric skills and abilities, a pre-test and a post-test were performed with the class during the teaching experiment. As a conclusion, it is inferred that the teaching experiment made it possible for the students to progress progressively in the construction of knowledge about remarkable polygons and quadrilaterals; and the teacher-researcher, reflect on the quality of geometry teaching when integrating technological resources when making teachers.
\end{abstract}

Keywords: Geometry. Teaching. Learning. Digital Technologies. 


\section{Referências}

BOGDAN, R. C.; BIKLEN, S. K. Investigação Qualitativa em Educação: Uma introdução à teoria e aos métodos. Coleção Ciências da Educação. Portugal: Porto. 1994.

BORSOI, C. Geogebra 3D no Ensino Médio: uma Possibilidade para a Aprendizagem da Geometria Espacial. Dissertação de Mestrado Profissional em Ensino de Matemática. Universidade Federal do Rio Grande do Sul. 2016.

BRASIL. Ministério da Educação. Base Nacional Comum Curricular. Segunda versão revista. Brasília. 2016.

CROWLEY, M. L. O modelo Van Hiele de desenvolvimento do pensamento geométrico. In: LINDQUIST, Mary, M. SHULTE, Albert, P. Aprendendo e Ensinando Geometria. São Paulo: Saraiva. 1994.

GRAVINA, M. A.; CONTIERO, L. O. Modelagem com o GeoGebra: uma possibilidade para a educação interdisciplinar? In: RENOTE: Revista Novas Tecnologias na Educação CINTED - UFRGS. v. 9. p. 01-10. 2011.

GRAVINA, M. A. Geometria Dinâmica uma nova abordagem para o ensino de Geometria. Anais do VII Simpósio Brasileiro de Informática na Educação. p. 1-13. Belo Horizonte, Nov. 1996.

\section{GUIMARÃES, G. G. A Dinâmica Cibercultural na Ressignificação do Processo de} Construção do Conhecimento: uma Proposta Metodológica para o Ensino de Geometria Espacial. Tese de Doutorado em Educação. Faculdade em Educação. Programa de PósGraduação em Educação. Universidade do Estado do Rio de Janeiro. Rio de Janeiro. 2013.

HEINEN. L.; BASSO, M. V. A. Geometria nos anos iniciais: uma proposta de EnsinoAprendizagem usando Geometria Dinâmica. Trabalho de conclusão do Curso de Especialização em Matemática, Mídias Digitais e Didática: tripé para a formação do professor de matemática. Programa de Pós- Graduação em Ensino de Matemática. Universidade Federal do Rio Grande do Sul. Porto Alegre. 2015.

MALTEMPI, M. V.. Educação matemática e tecnologias digitais: reflexões sobre prática e formação docente. Acta Scientiae. v. 10. n 1. p. 59 - 67. Canoas. 2008.

NOTARE, M. R.; BASSO, M. V. A. Tecnologia na Educação Matemática: trilhando o caminho do fazer ao compreender. In: RENOTE: Revista Novas Tecnologias na Educação CINTED - UFRGS. v. 10. $\mathrm{n}^{\circ}$ 3. dez. 2012.

OLIVEIRA, E. A. Relação Espaço-Plano: Uma intervenção Pedagógica para o Desenvolvimento do Pensamento Geométrico. Dissertação de Mestrado. Programa de PósGraduação em Educação. Faculdade de Ciências e Tecnologias, UNESP/Campus de Presidente Prudente. 2008.

SCHIRLO, A. C.; DA SILVA, S. C. R.; DE OLIVEIRA, M. C. D.; ISHIKAWA, E. C. M. Abordando a Geometria pelos níveis de Van Hiele com o auxílio de softwares educativos. 
Congreso Iberoamericano de Ciencia, Tecnología, Innovación y Educación. Artículo 1535. 2014.

SCHIRLO, A. C.; DA SILVA, S. C. R. Teoria de Van Hiele: um diálogo construtivo para as aulas de Geometria. In: II Simpósio Nacional de Ensino de Ciência e Tecnologia. Universidade Tecnológica Federal do Paraná - Programa de Pós-Graduação em Ensino de Ciência e Tecnologia. Artigo número: 49, 2010.

SILVA, R. S.; BARONE, D. A. C.; BASSO, M. V. A.. Modelagem matemática e tecnologias digitais: uma aprendizagem baseada na ação. In: Revista EMP (Educação Matemática e Pesquisa), v. 18, n. 1, p. 421-446. 2016.

VIEIRA, C. R. Reinventando a Geometria no Ensino Médio: uma abordagem envolvendo materiais concretos, softwares de Geometria Dinâmica e a Teoria de Van Hiele. Dissertação de Mestrado Profissional em Educação Matemática. Universidade Federal de Ouro Preto. Ouro Preto. 2010. 